American Journal of Environmental Sciences 4 (4): 285-288, 2008

ISSN 1553-345X

(C) 2008 Science Publications

\title{
Effect of Bruchid Beetles (Burchidius Arabicus Decelle) Infestation on the Germination of Acacia tortilis (Forssk.) Hayne) Seeds
}

\author{
M. Al Jabr Ahmed \\ Department of Plant Protection, College of Agriculture and Food Sciences, \\ King Faisal University, P.O. Box 420, Al-Hassa, 31982, Saudi Arabia
}

\begin{abstract}
The role of bruchid beetle infestation on seed germination of Acacia tortilis (Forssk.) Hayne) Mimosaceae under different incubation temperatures and degrees of scarification was studied under controlled conditions. Results indicate that seed germination was highest $(96 \%)$ in scarified seeds at $25-35^{\circ} \mathrm{C}$ incubation temperature, whereas, it was only $28 \%$ in intact seeds. Seeds infected by bruchid beetles with one or two holes did not germinate regardless of different incubation temperatures. X-ray results of $A$. tortilis seeds showed substantial consumption of endosperm and embryonic portions by the bruchid beetles resulting in one or two holes in the infected seeds curtailing seed germination. A unique method of identifying seed viability of A. tortilis by $\mathrm{X}$-ray studies is reported.
\end{abstract}

Key words: Bruchid beetles, germination, scarification, Acacia tortilis, temparature

\section{INTRODUCTION}

Mature Acacia tortilis trees are considerd an important forage and shade source in rangeland of the arid and semi arid regions. A. tortilis trees remain green during the long dry season when many range species become dry and unproductive ${ }^{[1]}$. The factors which affect seed germination of Acacia species in a given micro environment are water availability, soil type, seed dormancy and insect infestation ${ }^{[2,3]}$. Many Acacia species are subjected to infestation by bruchid beetles of the family Bruchidae (Coleoptera). Predation by bruchid beetles, which lay their eggs on ripening pod has been shown to cause negative effect on seed viability $^{[4-8]}$. The larvae of bruchid beetles enter the seeds by drilling and feeds on the embryo and endosperm leaving most of the infested seeds nonviable, which may threaten Acacia population ${ }^{[4]}$.

Many species showed substantial reduction in seed germination under bruchid beetles infestation $2.5 \%$ in A. tortilis ${ }^{[9]}, 0.5$ in A. nilotica ${ }^{[10]}$ and $2.1 \%$ in $\mathrm{A}$. roddiaba $^{[11]}$

Seeds are the only means for propagation of A. tortilis, infestation by bruchid beetles could present a serious problem for seed germination. The objective of the present study was to evaluate the role of bruchid beetles on seed viability and seed germination under different incubation temperatures and a method to identify viable seeds by X-ray studies.

\section{MATERIALS AND METHODS}

Pods of Acacia (Acacia tortilis (Forssk.) Hayne) were collected from well developed tree populations in the eastern province of Saudi Arabia during May, 2003. Five Acacia trees representing the whole population were selected and considered as replicates. Pods Collected from each tree were dried in the open for two weeks and shattered manually. Seeds from each tree were separated into the following categories:

- Control, cleaned intact seeds without any treatment

- Scarified seeds- where, mechanical scarification of cleaned intact seeds were done by placing them in wood saw dust $\left(50 \mathrm{~cm}^{3}\right)$ for one minute

- Infested seeds with one hole

- Infested seeds with two holes

Fifty infested seeds from each tree with one or two holes were subjected to breeding until the complete insect was developed and identified while seeds of all categories were stored in bags at $4 \pm 1^{\circ} \mathrm{C}$ until the start of the experiment.

A composite sample(100 seeds) from each category were $\mathrm{x}$ rayed to determine whether seeds are filled or empty. Setting for X-raymachine were $40 \mathrm{~mA}$ and $15 \mathrm{Kv}$ and exposure time was 1 second. Exposures were subjected to examination under florescent light to determine seed viability by evaluating seed density.

Corresponding Author: M. Al Jabr Ahmed, Department of Plant Protection, College of Agriculture and Food Sciences, King Faisal University, P.O. Box 420, Al-Hassa, 31982, Saudi Arabia 
Seeds, which exhibited brightness in the X-ray sheet are considered viable.

During the first week of Jan, 2005, stored seeds from each category were sown in $1.0 \mathrm{~L}$ plastic air tight disposable container covered with $2.0 \mathrm{~mm}$ dry washed sand. Containers were irrigated with distilled water to field capacity and incubated in a programmed refrigerated incubator on $12 \mathrm{~h}$ light: $12 \mathrm{~h}$ dark (2000 Lxsylvonic cool white florescent lamps) with 2 incubation temperatures; $15-25$ and $25-35^{\circ} \mathrm{C}$ (darklight). Treatment combinations were replicated 5 times and arranged as a factorial experiment in a completely randomized design. Germination percentages were recorded every three days for 30 days after sowing. No further germination was observed six days later (36 days). Thereafter, the experiment was terminated. A seed considered germinated when the seedling had emerged from the soil. Germinated seeds were discarded after counting.

Collected data were subjected to the analysis of variance (ANOVA), according to ${ }^{[12]}$. Treatment means were compared using the Bays Least Significant Difference test (BLSD) according to ${ }^{[13]}$. Computations and statistical analysis were done using $\mathrm{SAS}^{[14]}$.

\section{RESULTS AND DISCUSSION}

Hard seed coats of Acacia species cause physical seed dormancy which may delay and reduce seed germination ${ }^{[15,16,3]}$. The presence of hard seed coat in Acacia species interfere with water imbibition causing a reduction in seed germination ${ }^{[17]}$. Seeds of Acacia species usually showed infestation with bruchid beetles of the family Bruchidae. Identification of the insect in the present study showed infestation with Burchidius arabicus Decelle. Adult females of bruchid beetles lay their eggs on the pods and the larvae enter the seed by drilling small holes. It has been speculated that those holes could over come physical seed dormancy of Acacia species because they will permit water and gases to enter easily to infestated seeds. Infestation with bruchid beetles have been reported to show such promotive effects on early germination and establishment of Acacia sieberiana ${ }^{[5]}$.

Results of the present study showed that seed germination was only $28 \%$ in intact seeds, while $93 \%$ was noticed in scarified seeds with the highest germination percentage $(96 \%)$ noticed under $25-35^{\circ} \mathrm{C}$ incubation temperature (Fig. 1). Mechanical scarification causes cracks on the seed coats, facilitating easy movement of water and gases promoting germination ${ }^{[18,20]}$. On the other hand, no germination was noticed under bruchid beetles infestation in seed

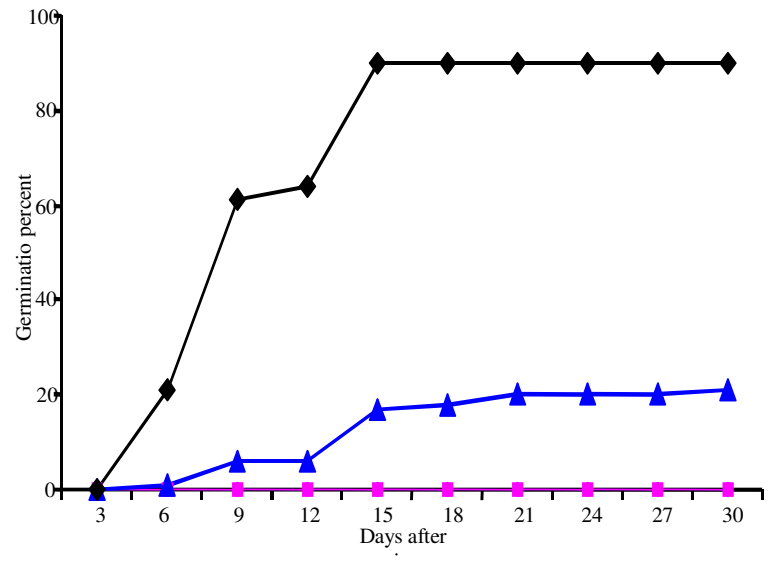

(a)

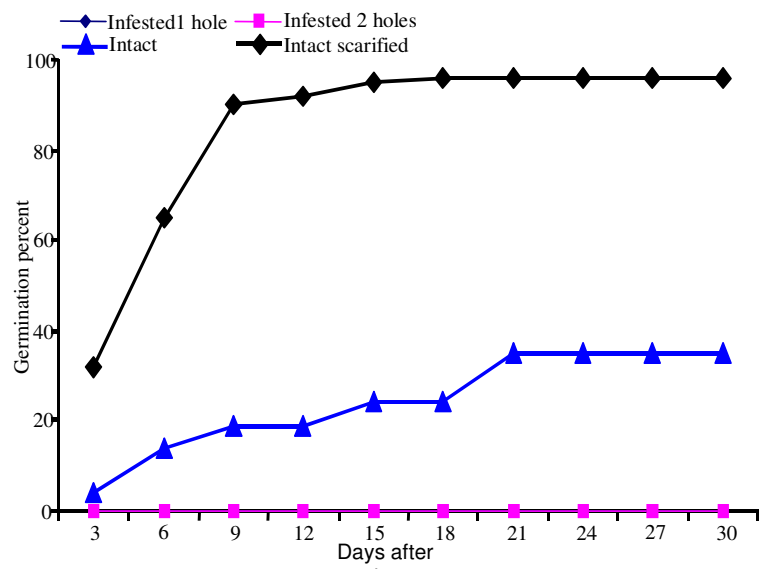

(b)

Fig. 1: Germination percent of intact and infested Acacia totilis seeds under incubation temperature of (a) $15-25^{\circ} \mathrm{C}$ and (b) $25-35^{\circ} \mathrm{C}$

with either one or two holes under both incubation temperatures. Different studies showed contrasting effects of bruchid infestation on seed germination. Rohner and Ward $^{[11]}$ found a lower germination percentage for infested Acacia raddiana seeds (2.1\%) versus $15.6 \%$ for intact seeds, while Miller ${ }^{[27]}$ found insignificant differences in germination percentage between infested $(2.5 \%)$ and intact $(1.5 \%)$ seeds of A. tortilis. Mucungazi ${ }^{[5]}$ found that bruchid beetles significantly reduced germination and seedling establishment of A. gerrardii, while they promoted germination of A. sieberiana.

It seems that negative effects of bruchid beetle infestation depends primarily on the consumption of the embryo by the larvae and secondarily on the proportion of cotyledons eaten ${ }^{[21]}$. Bruchid beetles larvae can exploit a considerable proportion of the cotyledons and 


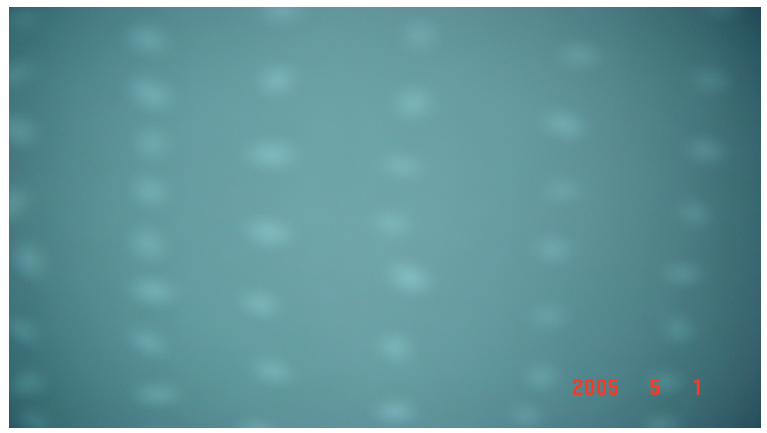

(a)

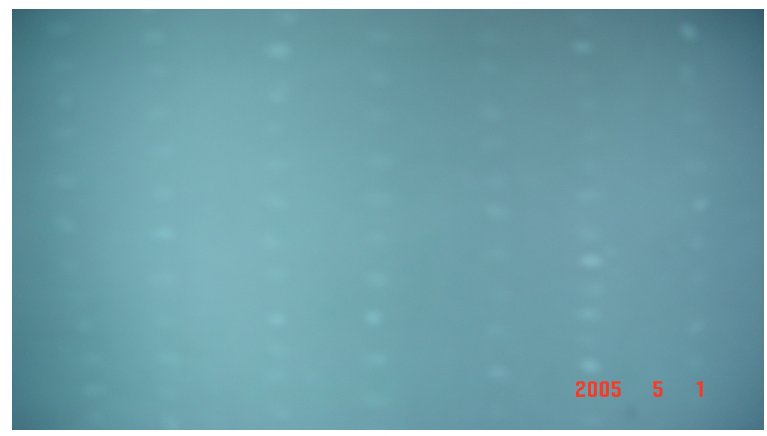

(b)

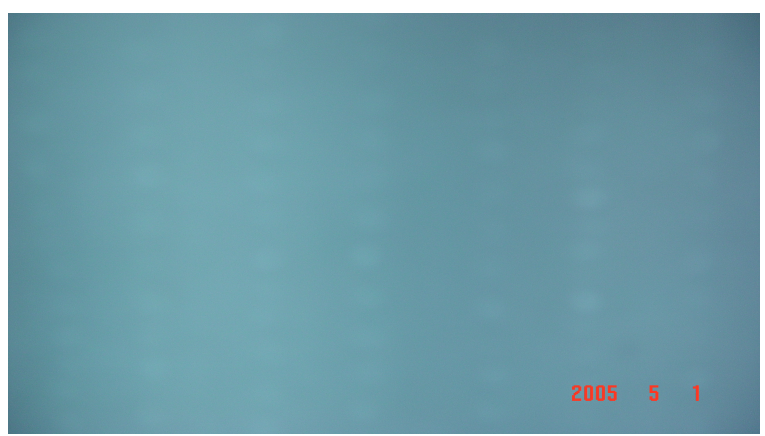

(c)

Fig. 2: (A) X-ray sheets of Acacia tortilis seeds, intact seeds, (B) infested one hole, (C) infested 2 holes

thus infestations can have an enormous negative effects on Acacia seeds viability and seedling vigour ${ }^{[22,11]}$. Some bruchid infested seeds remain viable if the embryo is not damaged ${ }^{[23]}$.

In the present study, X-rayof A. tortilis seeds showed substantial consumption of endosperm and embryonic parts by the bruchid beetles creating one or two holes in the seeds (Fig. 2). Visual examination of seed showed that bruchid beetles had no selective pattern of position attack which may give a chance of seed viability if the consumption did not involve the embryo. However, the infested seed did not germinate due to severe exploitation of embryonic parts by the bruchid beetles. Seed germination was partially limited due to physical seed dormancy even under sufficient water supply, while bruchid beetles damage, however appeared to be the primary factor preventing seed germination. One interesting aspect noted in the X-ray study was the brightness emitted by the intact seeds as compared to the infested seed with holes where no brightness was seen. This method can be utilized to identify viable seeds.

Our personal observation indicate that $A$. tortilis pods are indehiscent (pods drop off the tree and do not split). In this case, the seeds may remain in the pod until they are eaten, infested, trodden on, or degraded by fungal attack ${ }^{[24]}$. According to Rohner and Ward ${ }^{[11]}$, infestation level in A. tortilis did not differ due to whether the pod on the tree or in the ground. Infestation level of A. tortilis was described to be $99 \%^{[25]}, 96.2 \%{ }^{[11]}$. Infestation by bruchid beetles have been thought to be one of the reasons that Acacia species produce huge amount of seeds ${ }^{[26]}$. Miller ${ }^{[27]}$ indicates that $92 \%$ of A. tortilis pods were consumed by large herbivores. Ingestion of Acacia seed due to the consumption of pods by herbivores may kill bruchid larvae at early stage development within the seeds through the effects of stomach acids with out destroying the seeds ${ }^{[22]}$. Moreover stomach acid may improve Acacia seed germination. Acid scarification was reported to show $96 \%$ germination in A. tortilis ${ }^{[3]}$. According to Baskin and Baskin ${ }^{[18]}$ acid scarification increased seed permeability to water which promoted germination. Alternatively, herbivores may positively affect seed germination of $A$. tortilis due to the fact that they may remove pods from the tree prior of infestation.

Manipulation of seed predators is unlikely to be suitable option in rangeland of Saudi Arabia. Preventing infestation by bruchid beetles during pod bearing stage of $A$. tortilis through good range management could reduce seed insect predation and would possibly result in higher germination and better establishment of $A$. tortilis seedling.

It can be concluded that infestation of $A$. tortilis seeds by bruchid beetles is deleterious to seed germination. However, scarification and incubation temperature play a major role in enhancing germination of $A$. tortilis seeds. X-ray studies could be employed to identify seed viability.

\section{REFERENCES}

1. Lefroy, E.C., P.R. Dann, J.H. Wildin, R.N. Wisley-Smith and A.A. McGowan, 1992. Trees and shrubs as sources of fodder in Australia. Agroforestry Systems, 20: 117-139. 
2. Clark, D.B., D.A. Clark and P.M. Rich, 1993. Comparative analysis of microhabitat utilization by samplings of nine tree species in neotropical rain Forest. Biotropica., 25: 397-407.

3. Al-Khateeb, S.A., 2005. Germination response of Acacia tortilis to seed treatments and incubation temperatures. Alexandria journal of agricultural research, 50 (1): 33-40.

4. El-Atta, H.A., 1993. The effect of Caryedon serratus Olivier (Col., Bruchidaee) on viability and germination of seeds of Acacia nilotica (L. Willd. Ex Del.) in the Sudan. Forest Ecology and Management, 57 (1-4): 169-177.

5. Mucungazi, P., 1995. Effects of bruchid beetles on germination and establishment of Acacia species. African Journal of Ecology, 33 (1): 64-70.

6. Miller, M.E., 1996. Dispersal of Acacia seeds by ungulates and ostriches in an African savanna. J. Trop. Ecol., 12: 345-356.

7. Walter, M. and S.J. Milton, 2003. The production, storage and viability of seeds of Acacia karroo and A. nilotica in grassy savanna in Kwazulu-Natal, South Africa. Afr. J. of Ecol., 41: 211-217.

8. Schelin, M. M. Tigabu, I. Eriksson, L. Sawadogo and P.C. Oden, 2004. Predispersal seed predation in Acacia macrostachya, its impact on seed viability and germination to scarification and dry heat treatments. New Forests, 27 (3): 251-267.

9. Miller, M.E., 1995. Acacia seed survival, seed germination and seedling growth followed pod consumption by large herbivores and seed chewing by rodents. Afr. J. Ecol., 33: 194-210.

10. Miller, M.E., 1994. Large African herbivores, bruchid beetles and their interaction with Acacia seeds. Oecologia, 97: 265-270.

11. Rohner, C. and D. Ward, 1999. Large mammalian herbivores and the conservation of arid Acacia stands in the Middle East. Conserv. Biol., 13: 1162-1171.

12. Gomez, K.A. and A.A. Gomez, 1984. Statistical procedures for Agricultural research. 2nd. Ed. John waliy and Sons.

13. Waller, R.A. and D.P. Duncan, 1969. A bays rule for symmetric multiple comparison problem. Amer. Stat. Assoc. J., Dec. 1485-1503.

14. SAS Institue, 2001. SAS for Windows, SAS user's guide: Statistics. Version 8.0 e. SAS Inst., Inc., Cary, North Carolina.
15. Teketay, D., 1998. Germination of Acacia origena, A. pilispina and Pterolobium stellautum in response to different pre-sowing seed treatments, temperature and light. Journal of Arid Environments, 38: 551-560.

16. Sy, A., M. Grouzis and P. Danthu, 2001. Seed germination on seven Sehelian legume species. J. of Arid Envir., 49: 875-882.

17. Bewley, J.D. and M. Black, 1982. Physiology and biochemistry of seeds in relation to germination. Viability, Dormancy and Environmental control. Springer-Verlag, Berlin. 2: 375.

18. Baskin, J.M. and C.C. Baskin, 1998. Anatomy of two mechanisms of breaking physical dormancy by experimental treatments in seeds of two North America Rhus spp. Amer. J. of Bot., 85: 1505-1515.

19. Girase, U.S., N.D. Jambhale and Y.B. Suryawanshi, 2002. Germination and seed dormancy studies in Acacia species. Seed Research, 30 (1): 39-42.

20. Venkatesh, A., K. Vanagamudi and R. Umarani, 2002. Standardization of suitable pre-treatments to break dormancy of Acacia nilotica. Indica seeds. Seed Research, 30 (2): 284-288.

21. Lamprey, H.F., G. Halvey and S. Makacha, 1974. Interactions between Acacia, bruchid beetles and large herbivores. East. Afri. Wildl. J., 12: 81-85.

22. Coe, M. and C. Coe, 1987. Large herbivores, Acacia trees and bruchid beetles. South Afr. J. Sci., 83: 624-635.

23. Barnes M.E., 2001. Seed predation, germination and seedling establishment of Acacia erioloba in northern Botswana. J. of Arid Envir., 49: 541-554.

24. Miller, M.E. and M. Coe, 1993. Is it advantageous for Acacia seeds to be eaten by ungulates? Oikos 66: 364-368.

25. Halevy, G., 1974. Effects of gazelles and seed beetles (Bruchidae) on germination and establishment of Acacia species. Ist. J. Bot., 23: $120-126$.

26. Sabiiti, E.N. and R.W. Wein, 1987. Fire and Acacia seeds: a hypothesis of colonization success. J. Ecol., 74: 937-946.

27. Miller, M.E., 1994. The fact of mature African Acacia pods and seeds during their passage from the tree to the soil. J. Trop. Ecol., 10: 183-196. 